\title{
Psychological Security of Firstborn Children under a Two-Child Policy
}

\author{
Danwen Chen $^{1, a}$ and Xu Zha ${ }^{2, b}$ \\ ${ }^{1}$ School of Education, Jianghan University, Sanjiaohu Road 8, Wuhan Economic \& Technological \\ Development Zone, Wuhan, Hubei, China \\ ${ }^{2}$ School of Education, Jianghan University, Sanjiaohu Road 8, Wuhan Economic \& Technological \\ Development Zone, Wuhan, Hubei, China \\ acdw@jhun.edu.cn, b649613327@qq.com
}

Keywords: two-child policy,firstborn children, psychological security

\begin{abstract}
This study surveys 256 adolescents aged 13-15 to understand firstborn children's psychological security and attitudes to their parents having a second child and further explore the correlation between such security and such attitudes under China's newly implemented two-child policy. The survey is conducted with the aid of two scales: Psychological Security Scale made by Cong Zhong and An Lijuan and self-made Questionnaire on Attitudes to Parents Having a Second Child. The data of the questionnaires are recorded in Excel sheets and analyzed with SPSS 20.0 through descriptive statistical analysis, variance analysis, rank correlation analysis and other statistical approaches. The results reveal a positive correlation between psychological security and attitudes to parents having a second child for firstborn children in their adolescence, where there are significant differences in age. It is finally suggested that the school should establish a psychological counseling room, a psychological vent room and an online parents-school contact platform, and employ a certain number of psychological counseling teachers. In this way, students can find a place to vent when in a bad mood, while the school can guide students to a higher level of psychological security by having them correctly face stressful life events and reduce anxiety, panic and other negative feelings. In addition, parents are advised to take their firstborn into account in their plan of having a second child. They should communicate more with their firstborn, allow for their inner feelings and prevent the thought that a second child will take away parental love.
\end{abstract}

\section{Definition of Psychological Security}

American humanistic psychologist Abraham Maslow defined psychological security as a feeling that consists of confidence, security and freedom detached from fear and anxiety and that particularly meets a person's various needs at present (and in the future). Maslow also drew upon his clinical practice and designed Security-Insecurity Inventory (S-I Inventory). Through an analysis of previous studies and empirical interviews with neurotic patients and normal people, Chinese scholars Cong Zhong and An Lijuan have given such a definition: A sense of security is a presentiment of risk that may occur to the body or mind as well as a feeling of power (or powerlessness) in response to such risk, which manifests itself as a kind of certainty and control. They have also designed a security scale for detection of neurosis as well as for testing and assessment of security in normal people. In this study, psychological security is defined as a sense of security, control and self-confidence that occurs to an individual in the presence of an objective thing or situation. It also involves a feeling of emotional, interpersonal satisfaction, stability and belonging.

\section{Research Purpose and Significance}

Among all the issues confronting those aged 13-15 in today's China, personal safety is no longer 
a prominent one in consideration of the anxiety and instability it brings. A variety of psychological issues have gradually come to the surface and become the focus of attention with the improvement of people's living standards. Social policy factors affect family factors; family factors then affect children's mental health. In 1979, China pursued a family planning policy under which all couples could only have one child (except minority couples, and rural families with a firstborn daughter). In 2011, a couple was allowed to have a second child if one of them is an only child. Since 2015, a two-child policy has been fully launched, which undoubtedly have effects on many families, particularly on families with children aged 13-15. Adolescents at such ages tend to generate negative mentality since they grow up being spoiled and self-centered in the one-child policy environment. Now that the state policy shifts to a two-child system, an addition of a new family member will lead to a huge sense of loss in firstborn children. The study aims to understand firstborn children's psychological security and attitudes to parents having a second child in the context of a fully implemented two-child policy, explore the correlation between such security and attitudes and discuss the factors influencing such security and attitudes, and thus give some suggestions on how to improve firstborn children's psychological security in the hope of providing some contributions to children's mental health education.

\section{Research Methodology}

\subsection{Research Subjects}

The subjects of this study are young boys and girls aged 13-15 who have been just into their adolescence. A total of 256 questionnaires are distributed on the site, and all of them are recovered, including 238 valid questionnaires (an effective recovery rate of 92.97\%). In the valid questionnaires, there are 77, 81 and 80 children respectively aged 13, 14 and 15. The situation about the subjects is shown in Table 1:

TABLE 1 Situation ABOUT THE SubJECTS

\begin{tabular}{|l|l|l|l|l|}
\hline \multicolumn{1}{|c|}{ Age } & \multicolumn{1}{|c|}{ Male } & \multicolumn{1}{c|}{ Female } & \multicolumn{1}{c|}{ Total } & $\begin{array}{c}\text { Only } \\
\text { Children }\end{array}$ \\
\hline 13 & 40 & 37 & 77 & 61 \\
\hline 14 & 43 & 38 & 81 & 65 \\
\hline 15 & 36 & 44 & 80 & 71 \\
\hline Total & 119 & 119 & 238 & 197 \\
\hline
\end{tabular}

\subsection{Research Method}

In this study, a questionnaire survey is used to investigate children aged 13-15.

\subsection{Research Tool}

The measurement of psychological security adopts the security scale designed by Cong Zhong and An Lijuan on the basis of Maslow's S-I Inventory. Security Questionnaire (SQ) consists of 16 items and 2 factors. The interpersonal security factor (Factor 1), comprising 8 projects, reflects the individual's security experience of interpersonal communication; the certainty and control factor (Factor 2), containing 8 projects, embodies the individual's prediction, certainty and control of life. The scale employs a five-grade scoring method and totals the scores of two factors. Its correlation coefficient with interpersonal trust, self-acceptance, self-evaluation and Maslow's S-I Inventory falls into the range of $0.235-0.682$, with good criterion validity. The correlation coefficients between the interpersonal security factor and the certainty and control factor and the total scale score are respectively 0.1857 and 0.1870 , with good content validity. There is a remarkable difference in scores of the security scale and its factors between normal people and neurotic patients; the scale thus displays good empirical validity distinguishing between normal people and neurotic patients. The scale's homogeneity reliability and test-retest reliability are respectively 0.857 and 
0.870 , indicating good reliability.

In order to investigate firstborn children's attitudes to parents having a second child, a self-made questionnaire is used in combination with a brief interview with the subjects to understand their attitudes and the relevant reasons. The questionnaire contains five questions on attitudes and reasons, and adopts a three-grade scoring method. For the reasons-related questions, answerers may give more than one answer.

\section{Results and Analysis}

4.1 Data Processing and Analytical Approaches

The questionnaire data are logged into Excel sheets for statistical analysis with the aid of SPSS 20.0. Statistical approaches adopted are descriptive statistical analysis, variance analysis and rank correlation analysis.

\subsection{Situation about Firstborn Children’s Psychological Security}

The results of descriptive statistical analysis of data obtained from SQ are shown in Table 2:

TABLE 2 RESUlTS OF DESCRIPTIVE STATISTICS OF SQ SCORES

\begin{tabular}{|l|l|l|l|l|}
\hline \multicolumn{1}{|c|}{ Factor } & Age & Frequency & \multicolumn{1}{c|}{ Mean } & \multicolumn{1}{c|}{$\begin{array}{c}\text { Standard } \\
\text { deviation }\end{array}$} \\
\hline \multirow{3}{*}{ Factor 1 } & 13 & 77 & 31.13 & 5.149 \\
\cline { 2 - 5 } & 14 & 81 & 29.26 & 5.329 \\
\cline { 2 - 5 } & 15 & 80 & 28.25 & 5.483 \\
\hline \multirow{3}{*}{ Factor 2 } & 13 & 77 & 28.69 & 5.587 \\
\cline { 2 - 5 } & 14 & 81 & 24.86 & 7.134 \\
\cline { 2 - 5 } & 15 & 80 & 24.09 & 5.909 \\
\hline \multirow{2}{*}{$\begin{array}{l}\text { Total security } \\
\text { score }\end{array}$} & 13 & 77 & 59.82 & 9.871 \\
\cline { 2 - 5 } & 14 & 81 & 54.12 & 10.779 \\
\cline { 2 - 5 } & 15 & 80 & 52.34 & 10.163 \\
\hline
\end{tabular}

In Table 2, the mean of the total security score of 13-year-olds, 14-year-olds and 15-year-olds is 59.82, 54.12 and 52.34, and the standard deviation of their respective mean happiness score is 1.125, 1.198 and 1.136. This suggests 13-year-olds have a higher level of psychological security than 14-year-olds and 15-year-olds.

\subsection{Age Differences in Psychological Security}

It can be seen from Fig. 1 that Factor 1, Factor 2 and total security score obtained by children aged 13-15 rank as follows: 13-year-old, 14-year-old and 15-year-old (from high to low). There are significant differences between the ages in the total security score and two factors, which show the psychological security level follows the order of 13-year-olds, 14 year-olds and 15-year-olds (from high to low).

TABle 3 ANAlysis of Age DifFERENCES IN SCORES

\begin{tabular}{|c|c|c|c|c|c|}
\hline Factor & Age & Mean & $\begin{array}{l}\text { Standard } \\
\text { deviation }\end{array}$ & $F$ & $P$ \\
\hline \multirow[t]{3}{*}{ Factor 1} & 13 & 31.13 & 5.149 & \multirow[t]{3}{*}{5.893} & \multirow[t]{3}{*}{0.00} \\
\hline & 14 & 29.26 & 5.329 & & \\
\hline & 15 & 28.25 & 5.483 & & \\
\hline \multirow[t]{3}{*}{ Factor 2} & 13 & 28.69 & 5.587 & \multirow[t]{3}{*}{12.098} & \multirow[t]{3}{*}{0.003} \\
\hline & 14 & 24.86 & 7.134 & & \\
\hline & 15 & 24.09 & 5.909 & & \\
\hline \multirow{3}{*}{$\begin{array}{l}\text { Total security } \\
\text { score }\end{array}$} & 13 & 59.82 & 9.871 & \multirow[t]{3}{*}{11.273} & \multirow[t]{3}{*}{0.000} \\
\hline & 14 & 54.12 & 10.779 & & \\
\hline & 15 & 52.34 & 10.163 & & \\
\hline
\end{tabular}




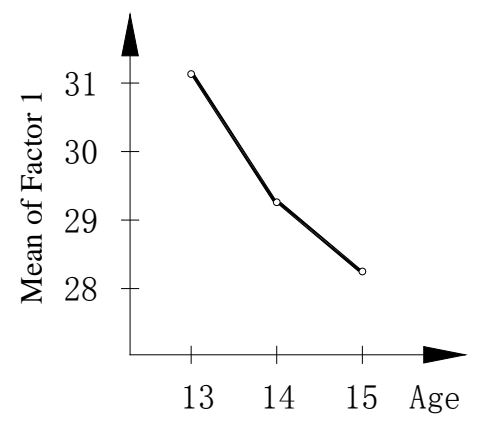

(a)

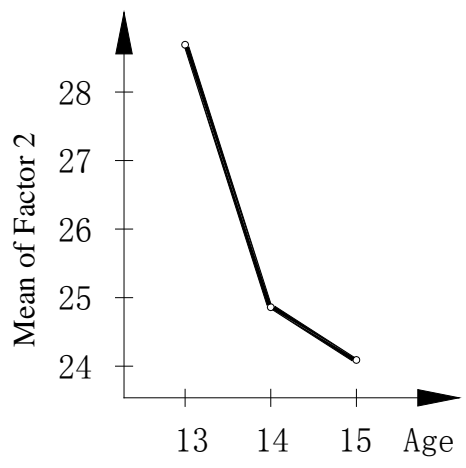

(b)

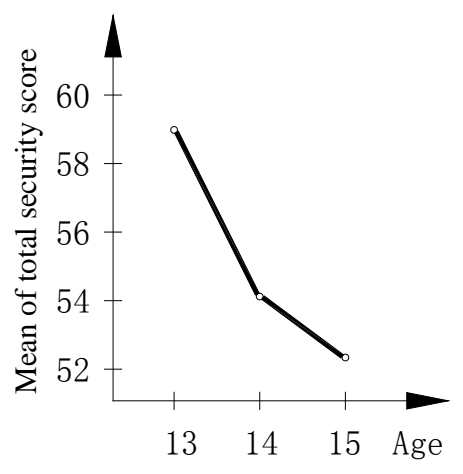

(c)

Fig.1. Mean of Factor 1, Factor 2 and Total Security Score Obtained by Children at Different Ages 4.4 Situation about Attitudes to Parents Having a Second Child

The statistics results of attitudes to parents having a second child are shown in Table 4:

TABLE 4 DESCRIPTIVE STATISTICS OF ATTITUDES

\begin{tabular}{|c|c|c|c|}
\hline Age & Cons & Neutrals & Pros \\
\hline 13 & 15 & 40 & 22 \\
\hline 14 & 10 & 36 & 35 \\
\hline 15 & 14 & 32 & 34 \\
\hline
\end{tabular}

As Table 4 shows, most of the subjects are neutrals for their parents having a second child, some are pros and only a few are cons.

TABLE 5 DESCRIPTIVE STATISTICS OF REASONS

\begin{tabular}{|c|c|c|c|}
\hline Reason & Cons & Neutrals & Pros \\
\hline Loneliness & $/$ & 36 & 46 \\
\hline Mutual help & $/$ & $/$ & 7 \\
\hline More family joy & $/$ & 8 & 25 \\
\hline Fondness for babies & $/$ & $/$ & $/$ \\
\hline Indifference & $/$ & 11 & $/$ \\
\hline Parents' decision & $/$ & 15 & $/$ \\
\hline $\begin{array}{c}\text { Presence of both pros } \\
\text { and cons }\end{array}$ & $/$ & 37 & $/$ \\
\hline Old age of parents & 5 & 6 & 3 \\
\hline Economic burden & 8 & 8 & $/$ \\
\hline Loss of parental love & 18 & 18 & 4 \\
\hline Dislike for babies & 9 & $/$ & 6 \\
\hline Others & 1 & & \\
\hline
\end{tabular}

4.5 Age Differences in Attitudes to Parents Having a Second Child

Table 6 Analysis of Age Differences in AtTitude SCORES

\begin{tabular}{|c|c|c|c|c|c|}
\hline Factor & Age & Mean & $\begin{array}{c}\text { Standard } \\
\text { Deviation }\end{array}$ & $\boldsymbol{F}$ & $\boldsymbol{p}$ \\
\hline \multirow{3}{*}{ Attitude } & 13 & 2.09 & 0.692 & \multirow{2}{*}{2.006} & \multirow{2}{*}{0.137} \\
\cline { 2 - 4 } & 14 & 2.31 & 0.683 & & \\
\cline { 2 - 4 } & 15 & 2.25 & 0.738 & & \\
\hline
\end{tabular}


As to attitudes to parents having a second child, 14 year-olds have better results than 15 year-olds and 15 year-olds have better results than 13 year-olds, but there is no significant difference between the ages.

\subsection{Correlation Analysis of Attitudes and Psychological Security}

TABLE 7 CORRELATION ANALYSIS

\begin{tabular}{|c|c|c|c|}
\hline & Attitude & Factor 1 & Factor 2 \\
\hline Factor 1 & $0.24^{*}$ & $/$ & $0.443^{* *}$ \\
\hline Factor 2 & $0.49^{* *}$ & $0.443^{* *}$ & $/$ \\
\hline $\begin{array}{c}\text { Total security } \\
\text { score }\end{array}$ & $0.28^{*}$ & $.710^{* *}$ & $0.763^{* *}$ \\
\hline
\end{tabular}

Through correlation analysis, the correlation coefficients between the total security score, Factor 1 and Factor 2 and attitude to parents having a second child are 0.28, 0.24 and 0.49, indicating a positive correlation between children's psychological security and their attitudes to parents having a second child.

\section{Discussions}

In terms of scores, children have high scores in the total score and two factors which denote a high level of psychological security. As for attitudes to parents having a second child, neutrals and pros greatly outnumber cons. What follows then is age-based discussion of adolescent firstborn children's psychological security and their attitudes to parents having a second child and the correlation between such security and attitudes.

\subsection{Age Differences in Firstborn Children’s Psychological Security}

Through one-way analysis of variance, it is found that 13-year-olds display a higher level of psychological security than 14-year-olds and that 14-year-olds display a higher level than 15-year-olds overall. This may be related to academic pressure and other factors: 13 year-olds are in their first year of junior high school and may have more care from teachers and parents. It is also noticed that since the school being surveyed is equipped with psychological teachers, those talking with psychology teachers after class are mostly 13 year-olds, though they are under lower academic pressure in this stage as their courses are not as difficult as those of 14-year-olds and 15-year-olds. The survey is carried out when the subjects are in their second semester; for 13-year-olds, they are more adapted to high school learning and life relative to the first semester. On the contrary, 14-year-olds and 15-year-olds are under higher academic pressure; particularly, 15-year-olds are about to take the senior high school entrance exam and are likely to generate more anxiety due to their own exam pressure and others' expectations.

\subsection{Correlation between Firstborn Children's Attitudes and Psychological Security}

The study finds that firstborn children's total security score and two factors are positively correlated with their attitudes to parents having a second child. That is to say, the higher level of psychological security firstborn children have, the more positive attitudes they will have to parents having a second child, which is consistent with the hypothesis of this study. A higher level of psychological security that adolescent firstborn children show also goes with a higher level of control, certainty and pressure resistance, or rather a lower level of uncertainty and anxiety, and accordingly a more positive attitude to parents having a second child. In factors influencing psychological security, the family environment that encourages mutual support and rational emotional expression are conducive to building adolescent firstborn children's psychological security. In other words, those with high psychological security may have more psychological support from their family and are thus more likely to support their parents having a second child. 
Meanwhile, children with strong psychological security also have high self-acceptance that makes for their support for the parents' decision.

\section{Conclusions}

For firstborn children in adolescence, their total psychological security scores have a positive correlation with their attitudes to parents having a second child; the interpersonal security factor has a significant correlation with the certainty and control factor in psychological security, and so does the two factors with the total security score; there are remarkable age differences in the two factors and total score of psychological security for adolescent firstborn children: in general, 13-year-olds have higher psychological security than 14-year-olds and 14-year-olds have higher security than 15-year-olds.

\section{Suggestions}

According to this study, some suggestions are given with a view to promoting education for adolescent children and improving their psychological security.

\subsection{Suggestions for the School}

First, the school should establish some organization for psychological care or ask teachers to help students vent negative feelings and guide them to correctly facing life events, reducing negative feelings and enhancing psychological security.

Second, teachers should pay attention to the psychological status of students, especially those in their adolescence. As they experience fast body growth, adolescent children may lose balance between psychological development and body growth, thereby leading to anxiety and panic. In the event of changes in the family, they may be unable to talk to parents. At this time, teachers should know about their physical and psychological characteristics and give more concern to their psychological state.

Third, there should be more contact between the school and parents. An online parents-school platform may be established to strengthen school-students-family contact for parents to timely communicate with the school. In this way, the school and parents can work together to provide effective care for students in terms of personal and psychological security, so that students have a platform to rely on to build psychological security.

\subsection{Suggestions for Parents}

First, many parents decide to have a second child with the full implementation of the two-child policy, but they should pay more attention to their first child, take into account their inner feelings and give positive responses to their feelings to avoid any negative feelings and mental problems.

Second, parents should develop children's independence and coping capacity. The majority of Chinese children are only children who can get spoiled easily. Thus, they should be trained to be independent in usual times.

\section{Deficiencies}

In this study, a questionnaire survey is conducted on children aged 13-15 to explore their attitudes to parents having a second child and their psychological security and the correlation between such attitudes and such security. In spite of some effective conclusions, there are deficiencies with this study due to some limitations.

The first deficiency is about the representativeness of the subjects. Due to time and manpower constraints, this study can only choose a small portion of students of a school as the subjects, when geographical restrictions also narrow the sample to about 250 students. Amid a small sample are also a lot of additional variables. The sample scope will be expanded in future studies to make the 
subjects more representative.

Then there is a lack of research tools. The self-made questions on attitudes to parents having a second child are relatively simple and cannot reflect other factors that affect such attitudes. A more detailed questionnaire will be designed in subsequent studies.

\section{References}

[1] An Lijuan, Cong Zhong, Wang Xin. High School Students' Sense of Security and the Related Factors [J]. Chinese Mental Health Journal, Oct. 2004: 717-719.

[2] An Lijuan, Cong Zhong. Review of Security Research [J]. Chinese Journal of Behavioral Medical Science, Jun. 2003: 98-99.

[3] An Lijuan, Yang Meirong. Preliminary Establishment of Reliability, Validity Test and Norm of High School Students' Sense of Security [J]. China Journal of Health Psychology, Jan. 2010: 76-77.

[4] Yang Chunyu, He Jianguo, Luo Changming, Guo Hong, Xu Zhimin, Chen Na, Zhao Anqin. Effects of Family Environment on Junior High School Students' Mental Health [J]. Chinese Journal of Health Psychology, Sep. 2010: 1127-1130.

[5] An Lijuan, Feng Jiangping. Status of Migrant Parents of Rural Junior High School Students and Its Impact on Psychological Security [J]. Educational Research and Experiment, Apr. 2015: 82-85.

[6] Huang Yan, Wang Haibin. Correlation between College Students' Negative Life Events and Psychological Security [J]. Soft Science of Heath, Jan. 2011: 50-52.

[7] Marie A. Eisenstein, April K. Clark. Political Tolerance, Psychological Security, and Religion: Disaggregating the Mediating Influence of Psychological Security [J]. Politics and Religion, 2014, 72.

[8] Haiyan Liu, Bo Zhang. An Investigative Research on the Status of Urban residents' Psychological Security [J]. J. Public Affairs, 2015, 153.

[9] Kelly, Séamas, Noonan, Camilla. Anxiety and Psychological Security in Offshoring Relationships: The Role and Development of Trust as Emotional Commitment [J]. Journal of Information Technology, 2008, 234.

[10]Elizabeth Kita. Public Safety, Psychological Security: A Practice-Informed Research Study Exploring How California Parole Agents Experience Their Work [J]. Smith College Studies in Social Work, 2015, 851. 